\title{
Home blood pressure monitoring with nurse-led telephone support among patients with hypertension and a history of stroke: a community-based randomized controlled trial
}

\author{
Sally M. Kerry MSc, Hugh S. Markus MD, Teck K. Khong MD, Geoffrey C. Cloud MBBS, Jenny Tulloch BSc, \\ Denise Coster MSc, Judith Ibison MSc, Pippa Oakeshott MD
}

See related commentary by Dawes and colleagues on page 11 and at www.cmaj.ca/lookup/doi/10.1503/cmaj.121819

\begin{abstract}
- ABSTRACT
Background: Adequate control of blood pressure reduces the risk of recurrent stroke. We conducted a randomized controlled study to determine whether home blood pressure monitoring with nurse-led telephone support would reduce blood pressure in patients with hypertension and a history of stroke.
\end{abstract}

Methods: We recruited 381 participants (mean age 72 years) from outpatient and inpatient stroke clinics between Mar. 1, 2007, and Aug. 31, 2009. Nearly half $(45 \%, 170)$ of the participants had some disability due to stroke. Participants were visited at home for a baseline assessment and randomly allocated to home blood pressure monitoring $(n=187)$ or usual care $(n=194)$. Those in the intervention group were given a monitor, brief training and telephone support. Participants who had home blood pressure readings consistently over target (target < 130/80 mm Hg) were advised to consult their family physician. The main outcome measure was a fall in systolic blood pressure after 12 months, mea- sured by an independent researcher unaware of group allocation.

Results: Despite more patients in the intervention group than in the control group having changes to antihypertensive treatment during the trial period $(60.1 \%$ [98/163] v. $47.6 \%$ [78/164], $p=0.02$ ), the fall in systolic blood pressure from baseline did not differ significantly between the groups (adjusted mean difference $0.3 \mathrm{~mm} \mathrm{Hg}, 95 \%$ confidence interval -3.6 to $4.2 \mathrm{~mm} \mathrm{Hg}$ ). Subgroup analysis showed significant interaction with disability due to stroke ( $p=0.03$ at 6 months) and baseline blood pressure ( $p=0.03$ at 12 months).

Interpretation: Overall, home monitoring did not improve blood pressure control in patients with hypertension and a history of stroke. It was associated with a fall in systolic pressure in patients who had uncontrolled blood pressure at baseline and those without disability due to stroke. Trial registration: ClinicalTrials.gov registration NCT00514800
Competing interests:

Hugh Markus and Geoffrey Cloud have received royalties as coauthors of Stroke Medicine published by Oxford University Press. Geoffrey Cloud has received consultancy fees from Boehringer Ingelheim and Bristol-Myers Squibb related to secondary prevention of stroke and educational travel bursaries from Boehringer Ingelheim.

No other competing interests were declared.

This article has been peer reviewed.

Correspondence to: Sally Kerry, s.m.kerry@qmul.ac.uk

CMAJ 2013. DOI:10.1503 /cmaj.120832
$\mathrm{W}$ orldwide about 15 million people have a stroke each year. ${ }^{1}$ Adequate control of blood pressure reduces the risk of recurrent stroke by up to $40 \% .{ }^{2}$ However, about 1 in 3 adults have blood pressure readings above recommended targets. ${ }^{3}$ Systematic reviews suggest that home monitoring is associated with reduced blood pressure ${ }^{4-7}$ and may improve compliance with treatment and encourage lifestyle changes. ${ }^{8}$ But the benefits tend to be modest. ${ }^{4,5}$ Co-interventions, such as patient education and support from health professionals, are important and may lead to intensification of antihypertensive treatment. ${ }^{8,9}$

Despite the importance of good control of blood pressure in patients with a history of stroke, little is known about home monitoring in this group. Physical and cognitive impairments resulting from stroke may adversely affect patients' compliance and ability to use the equipment successfully. We conducted a randomized controlled trial to determine whether home blood pressure monitoring with nurse-led telephone support was associated with reduced systolic blood pressure after 12 months in patients with hypertension and a history of stroke. Because PROGRESS (the Perindopril Protection Against Recurrent Stroke Study)2 showed that antihypertensive medications reduced the risk of recurrent stroke among patients with or without hypertension who had a history of stroke, we aimed to assess home monitoring in unselected patients with hypertension and a history of stroke across the blood pressure range. 


\section{Methods}

\section{Study design and participants}

We conducted a prospective, parallel-group, openlabel randomized controlled trial over 12 months. The trial protocol has been published previously. ${ }^{10}$ In brief, we recruited participants from 3 stroke services in London, United Kingdom, between Mar. 1, 2007, and Aug. 31, 2009. Participants were eligible for inclusion if they had a history of stroke or transient ischemic attack within the 9 months before enrolment and had hypertension. We defined hypertension as a blood pressure reading greater than $140 / 85 \mathrm{~mm} \mathrm{Hg}$ at the last clinic visit or treatment with antihypertensive medications, which was similar to definitions used in other studies. ${ }^{11,12}$ We excluded patients who were already enrolled in a trial; were severely ill or too frail; were already using a blood pressure monitor; had severe cognitive impairment (Abbreviated Mental Test score ${ }^{13}<7$ ); lived within about an hour's travel from the study centre, as defined by a list of postal codes; and did not speak English. We obtained written informed consent from the participants. The study was approved by the Wandsworth Research Ethics Committee.

\section{Randomization}

We used a computer-generated randomization sequence to implement stratified randomization based on age ( $<70 \mathrm{v} . \geq 70$ years), sex and disability resulting from stroke (Rankin disability score $0-1=$ no disability v. $\geq 2=$ some disability $^{14}$ ) with a $1: 1$ allocation using random block sizes of 4 and 6 . Allocation to the intervention or control group was contained within a sealed, numbered envelope and assigned to the participant by the trial administrator before the baseline visit. The research nurse opened the envelope after she completed the home baseline assessment. The participants, research nurse and trial administrator were not masked during the trial, but follow-up measurement of blood pressure after 6 and 12 months was done by an independent research assistant masked to group allocation.

\section{Study protocol}

Baseline blood pressure and pulse rate were measured at home by the research nurse with an automatic machine (Omron 705CP, Omron Healthcare UK Ltd., Milton Keynes, UK) with printout. Three readings were taken 1 minute apart, and the baseline blood pressure was recorded as the average of the last 2 readings. All patients with blood pressure at baseline greater than $150 / 90 \mathrm{~mm} \mathrm{Hg}$ were advised to see their family physician. All family physicians were sent information about the study and a recommended target for home blood pressure of less than 130/80 $\mathrm{mm} \mathrm{Hg} .^{15}$
Baseline assessment included use of the EuroQol 5-dimension (EQ-5D) index ${ }^{16}$ to measure quality of life, and the FEAR (frequency of anxiety, enduring nature of anxiety, alcohol or sedative use, restlessness or fidgeting) Questionnaire ${ }^{17}$ to measure anxiety level. To assess medication use, we asked patients to produce all medications they were currently taking.

\section{Intervention}

Participants in the intervention group were given, free of charge, an Omron M6 blood pressure monitor with appropriate-sized cuff (Omron Healthcare UK Ltd.). The participant, care provider or both were taught how to take blood pressure readings in the unaffected arm using a standardized method. ${ }^{18}$ They were advised to take 3 readings, 1 minute apart, daily for the first week, then weekly, and to record readings in a booklet. Participants were advised that their home blood pressure should be less than 130/80 mm Hg. ${ }^{15}$ This was also stated on a label stuck on the monitor. The nurse telephoned participants after a week and revisited after a month to check technique and review blood pressure readings. The nurse also telephoned at 3 and 9 months (and at 6 months if the reading taken by the research assistant was elevated). Participants whose blood pressure was consistently above target were advised to see their physician and to take their booklet. ${ }^{10}$ The nurse did not telephone the physician herself but provided telephone support to the patient twice weekly until the target pressure was reached.

Participants in the control group received usual care from their physician but no intervention from the nurse. The study administrator telephoned control participants after 3 and 9 months to check on their well-being, but no advice on blood pressure was given.

\section{Outcome measures}

The primary outcome measure was change in mean systolic blood pressure after 12 months. We selected systolic rather than diastolic blood pressure because it is a better predictor of stroke risk. ${ }^{20}$ Secondary outcome measures were change in mean systolic blood pressure after 6 months; change in mean diastolic blood pressure; number of antihypertensive drugs, treatment changes and primary care consultations; and change in EQ5D and FEAR scores.

An independent research assistant unaware of group allocation visited participants at home after 6 and 12 months and measured their blood pressure as at baseline. At the 12-month visit, a second questionnaire was administered. The number of primary care consultations per year was obtained from participants' reports at 12 
months; for a subset of 84 participants, this number was validated against family practice electronic medical records. ${ }^{19}$

\section{Statistical analysis}

A sample of 322 was required to detect a difference of $5 \mathrm{~mm} \mathrm{Hg}^{5}$ in change in mean systolic blood pressure over 12 months between the intervention and control groups, with $80 \%$ power using a 5\% significance level, assuming the standard deviation (SD) was $\pm 16 \mathrm{~mm} \mathrm{Hg} .{ }^{21,22}$ Allowing for a $10 \%$ loss to follow-up, we needed to recruit 360 participants. In March 2009, the Data
Monitoring Committee agreed that the sample size needed to be increased to 380 to allow for a $5 \%$ death rate.

All patients who had complete data on blood pressure were included in the analysis at each time point. We used a regression model to compare change in mean systolic blood pressure over the year between the intervention and control groups after adjusting for baseline blood pressure, age of 70 years or older, sex and presence of disability (Rankin score $\geq 2$ ). Because self-monitoring may present particular challenges in patients with disability and a history of stroke, prespecified

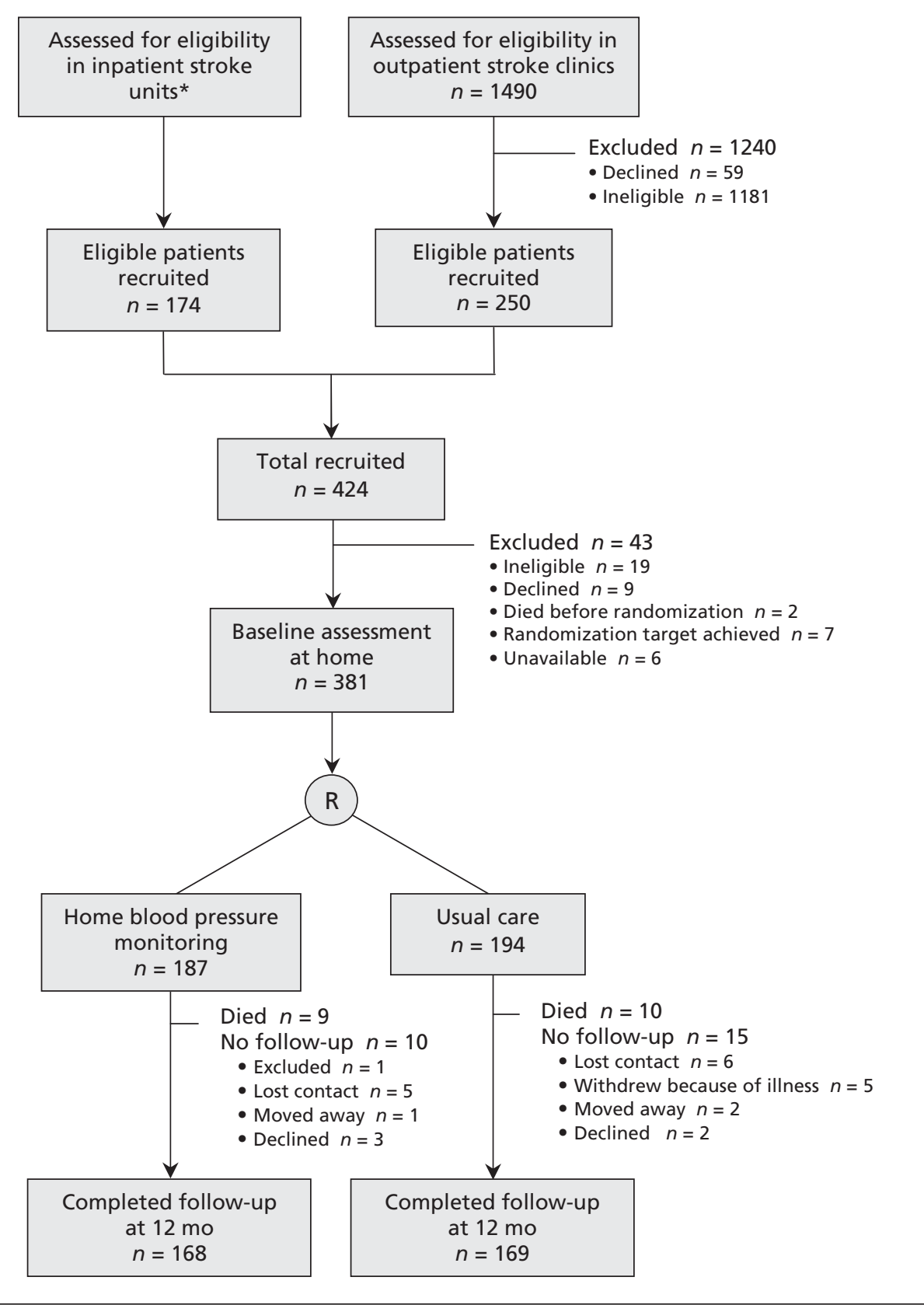

Figure 1: Selection of patients for inclusion in the study. $\mathbf{R}=$ randomization. * No information is available about the number of patients assessed or approached. 
subgroup analysis ${ }^{10}$ examined the effect of disability on change in systolic blood pressure by adding this factor and its interaction with the intervention effect to the regression model. Because the intervention may be more effective in patients with more elevated blood pressure, and to aid comparison with other studies, ${ }^{23,24}$ we did a post-hoc exploratory analysis of the effect of monitoring in patients with blood pressure at baseline greater than 140/90 $\mathrm{mm} \mathrm{Hg}$ and less than 200/100 $\mathrm{mm} \mathrm{Hg}$, versus 140/90 mm Hg or less.

\section{Results}

\section{Study participants}

The selection of patients for our study is summarized in Figure 1. Of 1490 patients assessed in the outpatient clinics, 309 were eligible for inclusion and $250(80.9 \%)$ of them agreed to take part. An additional 174 patients were recruited from inpatient stroke units. Before randomization, 43 of the 424 patients recruited for the study were excluded because they were not eligible $(n=19)$, they did not want to participate $(n=9)$, they died before randomization $(n=2)$, the randomization target was achieved $(n=7)$, or they were unavailable $(n=6)$. The 381 participants came from 165 general practices (range 1-11 patients per practice) and were randomly assigned to home monitoring $(n=187)$ or usual care $(n=194)$.

Nineteen patients $(5.0 \%)$ died during the follow-up period. Of the remaining 362 patients, $337(93.1 \%)$ had their blood pressure remeasured at home after 12 months and were included in the analysis of the primary outcome. The proportion of patients who completed follow-up was similar in the intervention and control groups $(94.7 \%$ and $92.3 \%$, respectively). Participants who did not complete follow-up were similar to the remainder, except they were less likely to score 10/10 on the Abbreviated Mental Test at recruitment (76.7\% v. $88.3 \%, p=0.03$; Appendix 1, available at www.cmaj.ca/lookup/suppl/doi:10.1503/cmaj $.120832 /-/ D C 1)$. The age of those who completed follow-up ranged from 30 to 94 (mean 72) years; $77(22.8 \%)$ were from ethnic minorities, and 151 (44.8\%) had some disability due to stroke. Baseline characteristics were similar between the study groups except that participants in the intervention group tended to have higher blood pressure readings at baseline (Table 1).

\section{Participants' experience of home blood pressure monitoring}

Of the 168 participants in the home monitoring group, $51(30.4 \%)$ required the help of a care provider to take their blood pressure. After 1 month, the mean blood pressure readings were systolic $133.4(\mathrm{SD} \pm 15.9) \mathrm{mm} \mathrm{Hg}$ and diastolic $72.4(\mathrm{SD} \pm 10.8) \mathrm{mm} \mathrm{Hg}$. The nurse made on average 3.8 (range 0-13) telephone calls to each patient during the follow-up period, of which 0.9 (range 0-12) were about high readings. At 12 months, $126(75.0 \%)$ of the patients said they or their care provider were still monitoring weekly. Patients with no disability were more likely than those with some disability to have recorded a full set of readings in the previous 4 weeks $(54.8 \%$ [51/93] v. 38.7\% [29/75]; $p=0.04$ ).

\section{Effect of home monitoring on blood pressure}

After adjustment for baseline blood pressure, we found no significant difference between the intervention and control groups in the mean fall in systolic blood pressure after 12 months ( $0.3 \mathrm{~mm} \mathrm{Hg}, 95 \%$ confidence interval -3.6 to 4.2 ; Table 2). Home monitoring was associated with a significantly greater reduction in blood pressure at 6 months but not at 12 months in patients without disability than in those with some disability. It was also associated with a significantly greater reduction in systolic blood pressure at 12 months in patients whose baseline blood pressure readings were higher than $140 / 90 \mathrm{~mm} \mathrm{Hg}$ and less than $200 / 100 \mathrm{~mm} \mathrm{Hg}$ than in those with normal blood pressure at baseline ( 8 patients with baseline blood pressure $\geq 200 / 100 \mathrm{~mm} \mathrm{Hg}$ were excluded from this analysis).

In terms of other outcomes, home monitoring had little effect on diastolic blood pressure (Appendix 2, available at www.cmaj.ca/lookup /suppl/doi:10.1503/cmaj.120832/-/DC1). Although patients were not masked, the independent research assistant reported being unaware of the allocation status of 292 out of 305 (95.7\%; this information was not recorded for the first 21 patients followed up) of the participants at the time of blood pressure measurement. More patients in the intervention group than in the control group had changes to their antihypertensive treatment during the trial $(60.1[98 / 163]$ v. $47.6 \%$ [78/164]; $p=0.02$ ) (Table 3). However, there was no difference between the groups in the number of medications per patient. Among the 133 patients with uncontrolled hypertension at baseline (> 140/90 mm Hg), 55 (75.3\%) of those in the home monitoring group had medication changes, as compared with $34(53.1 \%)$ of controls $(p=0.008)$.

\section{Quality of life and adverse events}

At 12 months, participants had significantly lower EQ-5D scores than at baseline (Table 4), and a higher proportion were deemed to have anxiety according to their FEAR score $(18.1 \%$ at 
Table 1: Baseline characteristics of 381 participants with hypertension and a history of stroke randomly assigned to home blood pressure monitoring (intervention) or usual care (control)

\begin{tabular}{|c|c|c|}
\hline \multirow[b]{2}{*}{ Characteristic } & \multicolumn{2}{|c|}{ Group; no. (\%) of participants* } \\
\hline & $\begin{array}{l}\text { Control } \\
n=194\end{array}$ & $\begin{array}{l}\text { Intervention } \\
\quad n=187\end{array}$ \\
\hline Age, yr, mean \pm SD & $72.6 \pm 11.4$ & $71.1 \pm 12.6$ \\
\hline Sex, male & $108(55.7)$ & $111(59.4)$ \\
\hline \multicolumn{3}{|l|}{ Ethnicity } \\
\hline White & $141(72.7)$ & $150(80.2)$ \\
\hline Black & 29 (14.9) & $20(10.7)$ \\
\hline Asian & $14(7.2)$ & $8(4.3)$ \\
\hline Other & $10(5.2)$ & $9(4.8)$ \\
\hline $\begin{array}{l}\text { Index of Multiple Deprivation score, } \dagger \\
\text { mean } \pm \text { SD }\end{array}$ & $19.3 \pm 10.1$ & $17.5 \pm 10.7$ \\
\hline \multicolumn{3}{|l|}{ Rankin disability score } \\
\hline 0 (no symptoms) & $56(28.9)$ & $51(27.3)$ \\
\hline $\begin{array}{l}1 \text { (minor symptoms that do not affect } \\
\text { activities) }\end{array}$ & $54(27.8)$ & $50(26.7)$ \\
\hline 2 (unable to do all previous activities) & $50(25.8)$ & $53(28.3)$ \\
\hline$\geq 3$ (need help with self-care) & $34(17.5)$ & $33(17.6)$ \\
\hline Abbreviated Mental Test score 10/10 & $\begin{array}{c}n=191 \\
171(89.5)\end{array}$ & $\begin{array}{c}n=184 \\
155(84.2)\end{array}$ \\
\hline Anxiety (positive FEAR score) & $\begin{array}{l}n=190 \\
34(17.9)\end{array}$ & $\begin{array}{l}n=186 \\
33(17.7)\end{array}$ \\
\hline $\begin{array}{l}\text { Type of cerebrovascular event in the } 9 \text { mo } \\
\text { before recruitment }\end{array}$ & $n=168$ & $n=170$ \\
\hline Transient ischemic attack & $50(29.8)$ & $58(34.1)$ \\
\hline Ischemic stroke & $107(63.7)$ & $98(57.6)$ \\
\hline Hemorrhagic stroke & $8(4.8)$ & $12(7.1)$ \\
\hline Both types of stroke or unknown & $3(1.8)$ & $2(1.2)$ \\
\hline Recruited within 4 mo after stroke & $\begin{array}{l}n=183 \\
95(51.9)\end{array}$ & $\begin{array}{l}n=178 \\
95(53.4)\end{array}$ \\
\hline \multicolumn{3}{|l|}{ Blood pressure, $\mathrm{mm} \mathrm{Hg}$, mean $\pm \mathrm{SD}$} \\
\hline Systolic & $135.8 \pm 20.7$ & $140.3 \pm 21.3$ \\
\hline Diastolic & $72.8 \pm 11.1$ & $75.5 \pm 12.4$ \\
\hline Body mass index, mean \pm SD & $\begin{array}{c}n=169 \\
27.3 \pm 4.9\end{array}$ & $\begin{array}{c}n=162 \\
28.1 \pm 5.6\end{array}$ \\
\hline Current smoker & $21(10.9)$ & $25(13.4)$ \\
\hline \multicolumn{3}{|l|}{ Patient-reported medical history } \\
\hline Diabetes§ & $44(22.7)$ & $39(21.0)$ \\
\hline Atrial fibrillationף & $37(19.2)$ & $46(25.0)$ \\
\hline $\begin{array}{l}\text { Stroke or transient ischemic attack } \\
\text { (before presenting event) }\end{array}$ & $54(27.8)$ & $61(32.6)$ \\
\hline Angina or heart attack** & $37(19.2)$ & $39(21.1)$ \\
\hline No. of antihypertensive drugs, mean \pm SD & $1.7 \pm 1.0$ & $1.9 \pm 1.1$ \\
\hline \multicolumn{3}{|c|}{$\begin{array}{l}\text { Note: FEAR = frequency of anxiety, enduring nature of anxiety, alcohol or sedative use, restlessness or fidgeting; }{ }^{17} \mathrm{SD}=\text { standard } \\
\text { deviation. } \\
\text { *Unless stated otherwise. } \\
\text { †The Index of Multiple Deprivation } 2007 \text { scale is a measure of poverty and is based on postal codes and ranges from } 0.37 \text { to } \\
85.46 \text {. A higher score indicates higher deprivation. Further information can be found at www.communities.gov.uk/communities } \\
\text { /research/indicesdeprivation/deprivation } 10 / \\
\text { fSome patients had speech problems, but their comprehension was good and their inclusion was approved by the clinic doctor. } \\
\text { SInformation on diabetes was not provided by } 1 \text { patient in the intervention group. } \\
\text { qInformation on atrial fibrillation was not provided by } 1 \text { patient in the intervention group and } 3 \text { patients in the control group. } \\
\text { **Information on angina or heart attack was not provided by } 2 \text { patients in the intervention group and } 1 \text { patient in the control } \\
\text { group. }\end{array}$} \\
\hline
\end{tabular}


baseline v. $27.0 \%$ at follow-up); there was no significant difference in these measures between the groups.

The number of primary care consultations reported by participants did not differ significantly between the groups: mean $5.2(\mathrm{SD} \pm 4.6)$ per patient in the intervention group $(n=159)$ and $5.4(\mathrm{SD} \pm 5.3)$ in the control group $(n=$ $155)$; between-group difference 0.2 (95\% CI -0.9 to 1.3$)$. Validation against electronic medical records suggested a small $(20 \%)$ underestimation in reported consultations.

The proportion of participants who reported falls during the follow-up period did not differ significantly between the intervention $(19.0 \%$ $[n=32])$ and control $(17.2 \%[n=29])$ groups. The same was true for recurrent stroke $(6.1 \%$ $[n=11]$ and $8.1 \%[n=15]$, respectively).

\section{Interpretation}

Overall, home monitoring did not improve blood pressure control in this group of patients with hypertension and a history of stroke. However, it was associated with more changes in antihypertensive treatment during the trial, which suggested more active management in the intervention group. Patients with no disability were more likely than those with disability resulting from stroke to continue monitoring and had a signifi-

Table 2: Systolic blood pressure readings in intervention and control groups*

\begin{tabular}{|c|c|c|c|c|c|c|}
\hline \multirow[b]{2}{*}{$\begin{array}{l}\text { Variable; patient } \\
\text { group }\end{array}$} & \multicolumn{2}{|c|}{$\begin{array}{l}\text { Systolic pressure, } \mathrm{mm} \mathrm{Hg} \text {, } \\
\text { mean } \pm \text { SD }\end{array}$} & \multicolumn{2}{|c|}{$\begin{array}{l}\text { Mean fall from baseline } \\
(95 \% \mathrm{Cl}), \mathrm{mm} \mathrm{Hg}{ }^{\dagger}\end{array}$} & \multicolumn{2}{|c|}{$\begin{array}{l}\text { Adjusted } \neq \text { difference in mean fal } \\
(95 \% \mathrm{Cl}) \text {, intervention-control, } \\
\mathrm{mm} \mathrm{Hg}\end{array}$} \\
\hline & $\begin{array}{c}6 \mathrm{mo} \\
n=3529\end{array}$ & $\begin{array}{c}12 \mathrm{mo} \\
n=337\end{array}$ & $\begin{array}{c}6 \text { mo } \\
n=352\end{array}$ & $\begin{array}{c}12 \mathrm{mo} \\
n=337\end{array}$ & $\begin{array}{l}\text { Baseline } \\
\text { to } 6 \mathrm{mo}\end{array}$ & $\begin{array}{l}\text { Baseline } \\
\text { to } 12 \mathrm{mo}\end{array}$ \\
\hline \multicolumn{7}{|l|}{ All patients } \\
\hline Intervention, $n=168$ & $137.8 \pm 20.8$ & $138.5 \pm 20.8$ & $\begin{array}{c}2.8 \\
(-0.4 \text { to } 5.9)\end{array}$ & $\begin{array}{c}1.7 \\
(-1.4 \text { to } 4.8)\end{array}$ & $\begin{array}{c}-0.2 \\
(-3.9 \text { to } 3.5)\end{array}$ & $\begin{array}{c}0.3 \\
(-3.6 \text { to } 4.2)\end{array}$ \\
\hline Control, $n=169$ & $135.4 \pm 19.2$ & $136.7 \pm 20.3$ & $\begin{array}{c}0.6 \\
(-2.4 \text { to } 3.5)\end{array}$ & $\begin{array}{c}-0.7 \\
(-4.0 \text { to } 2.5)\end{array}$ & & \\
\hline \multicolumn{7}{|l|}{ Rankin score $\leq 1$} \\
\hline Intervention, $n=93$ & $137.3 \pm 20.3$ & $138.3 \pm 20.0$ & $\begin{array}{c}4.2 \\
(0.1 \text { to } 8.4)\end{array}$ & $\begin{array}{c}3.5 \\
(-0.6 \text { to } 7.6)\end{array}$ & $\begin{array}{c}3.4 \\
(-1.5 \text { to } 8.2)\end{array}$ & $\begin{array}{c}2.4 \\
(-2.9 \text { to } 7.6)\end{array}$ \\
\hline Control, $n=93$ & $137.9 \pm 20.7$ & $138.2 \pm 21.1$ & $\begin{array}{l}-1.9 \\
(-5.3 \text { to } 1.4)\end{array}$ & $\begin{array}{c}-1.4 \\
(-5.4 \text { to } 2.6)\end{array}$ & & \\
\hline \multicolumn{7}{|l|}{ Rankin score $\geq 2$} \\
\hline Intervention, $n=75$ & $138.4 \pm 21.5$ & $138.8 \pm 22.0$ & $\begin{array}{c}1.0 \\
(-3.9 \text { to } 6.0)\end{array}$ & $\begin{array}{c}-0.5 \\
(-5.3 \text { to } 4.2)\end{array}$ & $\begin{array}{c}-4.7 \\
(-10.2 \text { to } 0.8)\end{array}$ & $\begin{array}{c}-2.3 \\
(-8.1 \text { to } 3.5)\end{array}$ \\
\hline Control, $n=76$ & $131.9 \pm 16.5$ & $134.9 \pm 19.2$ & $\begin{array}{c}4.0 \\
(-1.1 \text { to } 9.2)\end{array}$ & $\begin{array}{c}0.1 \\
(-5.3 \text { to } 5.5)\end{array}$ & & \\
\hline Interaction $p$ value & & & & & $p=0.03$ & $p=0.2$ \\
\hline \multicolumn{7}{|c|}{$\begin{array}{l}\text { Baseline blood pressure } \\
>140 / 90 \text { and }<200 / 100 \mathrm{~mm} \mathrm{Hg}\end{array}$} \\
\hline Intervention, $n=68$ & $145.0(18.6)$ & $143.2(17.8)$ & $\begin{array}{c}9.3 \\
\text { (5.2 to } 13.5)\end{array}$ & $\begin{array}{c}11.2 \\
\text { (6.8 to } 15.7)\end{array}$ & $\begin{array}{c}1.6 \\
(-4.0 \text { to } 7.1)\end{array}$ & $\begin{array}{c}5.9 \\
(-0.1 \text { to } 11.9)\end{array}$ \\
\hline Control, $n=65$ & $145.8(17.8)$ & $147.8(18.8)$ & $\begin{array}{c}7.4 \\
(2.8 \text { to } 12.1)\end{array}$ & $\begin{array}{c}4.7 \\
(-0.5 \text { to } 9.8)\end{array}$ & & \\
\hline \multicolumn{7}{|c|}{$\begin{array}{l}\text { Baseline blood pressure } \\
\leq 140 / 90 \mathrm{~mm} \mathrm{Hg}\end{array}$} \\
\hline Intervention, $n=94$ & $131.5(19.0)$ & $132.8(19.0)$ & $\begin{array}{c}-5.4 \\
(-8.9 \text { to }-1.8)\end{array}$ & $\begin{array}{l}-6.6 \\
(-10.2 \text { to }-3.0)\end{array}$ & $\begin{array}{c}-1.9 \\
(-6.4 \text { to } 2.7)\end{array}$ & $\begin{array}{c}-2.5 \\
(-7.4 \text { to } 2.4)\end{array}$ \\
\hline Control, $n=102$ & $128.0(15.0)$ & $129.4(17.0)$ & $\begin{array}{c}-4.9 \\
(-7.8 \text { to }-1.9)\end{array}$ & $\begin{array}{c}-5.5 \\
(-8.9 \text { to }-2.1)\end{array}$ & & \\
\hline Interaction $p$ value & & & & & $p=0.4$ & $p=0.03$ \\
\hline \multicolumn{7}{|c|}{$\begin{array}{l}\text { Note: } \mathrm{Cl}=\text { confidence interval, } \mathrm{SD}=\text { standard deviation. } \\
\text { *Sensitivity analysis for missing values using multiple imputation did not change any of the findings (data not shown). } \\
\text { †Negative values indicate rise in blood pressure. } \\
\text { ₹Adjusted for stratification factors (age, sex and Rankin disability score) and baseline systolic blood pressure. } \\
\text { IData are given for the } 175 \text { intervention and } 177 \text { control patients followed up for } 6 \text { mo. }\end{array}$} \\
\hline
\end{tabular}


cantly greater reduction in systolic blood pressure at 6 months. In a post-hoc analysis, home monitoring was associated with a significantly greater reduction in systolic blood pressure in those with uncontrolled blood pressure at baseline than in those with controlled blood pressure at baseline.
The lack of overall benefit of home monitoring on blood pressure may have been due to a failure of implementation (using the monitor), a failure to effect change or heterogeneity in the treatment effect. Home monitoring depended on patients taking their blood pressure, recognizing

Table 3: Changes to antihypertensive treatment during follow-up among participants with complete medication data

\begin{tabular}{|c|c|c|c|}
\hline \multirow[b]{2}{*}{ Variable } & \multicolumn{2}{|c|}{ Group; no. (\%) of participants* } & \multirow[b]{2}{*}{$\begin{array}{c}\text { Difference in \% (95\% Cl), } \\
\text { intervention-control* }\end{array}$} \\
\hline & $\begin{array}{l}\text { Intervention } \\
n=163\end{array}$ & $\begin{array}{l}\text { Control } \\
n=164\end{array}$ & \\
\hline \multicolumn{4}{|l|}{ Medication changes at 6 mo } \\
\hline No change & $74(45.4)$ & $96(58.5)$ & $-13(-24$ to -2$) \S$ \\
\hline Decreased dose or no. of medications & $23(14.1)$ & $12(7.3)$ & $7(0$ to 13$)$ \\
\hline Increased dose or no. of medications & $44(27.0)$ & $38(23.2)$ & $4(-6$ to 13$)$ \\
\hline Other changet & $22(13.5)$ & $18(11.0)$ & $3(-5$ to 10$)$ \\
\hline \multicolumn{4}{|l|}{ Medication changes at 12 mo } \\
\hline No change & $65(39.9)$ & $86(52.4)$ & $-12(-23$ to -2$) \S$ \\
\hline Decreased dose or no. of medications & $23(14.1)$ & $14(8.5)$ & $6(-1$ to 12$)$ \\
\hline Increased dose or no. of medications & $48(29.4)$ & $42(25.6)$ & $4(-6$ to 14$)$ \\
\hline Other changet & $27(16.6)$ & $22(13.4)$ & $3(-5$ to 11$)$ \\
\hline \multicolumn{4}{|l|}{$\begin{array}{l}\text { No. of antihypertensive } \\
\text { medications per patient }\end{array}$} \\
\hline At baseline, $\neq$ mean \pm SD & $1.8 \pm 1.1$ & $1.6 \pm 1.0$ & \\
\hline At $12 \mathrm{mo}$, mean $\pm \mathrm{SD}$ & $2.1 \pm 1.2$ & $2.0 \pm 1.1$ & \\
\hline $\begin{array}{l}\text { Mean difference }(95 \% \mathrm{Cl}) \text { from } \\
\text { baseline }\end{array}$ & $0.3(0.1$ to 0.4$)$ & $0.4(0.2$ to 0.5$)$ & $0.1(-0.1$ to 0.3$)$ \\
\hline \multicolumn{4}{|c|}{$\begin{array}{l}\text { Note: } \mathrm{Cl}=\text { confidence interval, } \mathrm{SD}=\text { standard deviation. } \\
\text { *Unless stated otherwise. } \\
\text { tIncluded increased dose but reduced no. of drugs; increased no. of drugs but reduced dose; one drug stopped and another } \\
\text { started; and multiple changes. } \\
\text { fOnly } 15 \text { intervention and } 10 \text { control patients were not receiving treatment at baseline. Of } 312 \text { patients receiving treatment, } \\
239(76.6 \%) \text { were taking angiotensin-converting-enzyme inhibitors or angiotensin-receptor blockers, } 142(45.5 \%) \text { were taking } \\
\text { calcium-channel blockers, } 115(36.9 \%) \text { were taking diuretics, and } 79(25.3 \%) \text { were taking other antihypertensives. } \\
\text { \$p }<0.05 \text { for comparison between no change and change in medications. }\end{array}$} \\
\hline
\end{tabular}

Table 4: Change in quality of life at end of follow-up

\begin{tabular}{|c|c|c|c|c|c|}
\hline \multirow[b]{2}{*}{ Variable; patient group } & \multirow{2}{*}{$\begin{array}{c}\text { No. of } \\
\text { patients }\end{array}$} & \multicolumn{2}{|c|}{ EQ-5D score, ${ }^{*}$ mean \pm SD } & \multirow{2}{*}{$\begin{array}{l}\text { Difference from } \\
\text { baseline }(95 \% \mathrm{Cl})\end{array}$} & \multirow{2}{*}{$\begin{array}{c}\text { Between-group } \\
\text { difference }(95 \% \mathrm{Cl}) \text {, } \\
\text { intervention-controlt }\end{array}$} \\
\hline & & At baseline & At $12 \mathrm{mo}$ & & \\
\hline \multicolumn{6}{|l|}{ All patients } \\
\hline Intervention & 164 & $0.80 \pm 0.22$ & $0.67 \pm 0.27$ & $0.13(0.09$ to 0.15$)$ & \multirow[t]{2}{*}{$0.02(-0.03$ to 0.06$)$} \\
\hline Control & 164 & $0.79 \pm 0.22$ & $0.67 \pm 0.27$ & $0.12(0.10$ to 0.17$)$ & \\
\hline \multicolumn{6}{|l|}{ Rankin score $\leq 1$} \\
\hline Intervention & 91 & $0.87 \pm 0.20$ & $0.76 \pm 0.22$ & $0.11(0.06$ to 0.15$)$ & \multirow[t]{2}{*}{$0.00(-0.06$ to 0.06$)$} \\
\hline Control & 90 & $0.88 \pm 0.15$ & $0.76 \pm 0.21$ & 0.11 (0.07 to 0.14$)$ & \\
\hline \multicolumn{6}{|l|}{ Rankin score $\geq \mathbf{2}$} \\
\hline Intervention & 73 & $0.72 \pm 0.22$ & $0.56 \pm 0.27$ & $0.16(0.11$ to 0.21$)$ & \multirow[t]{2}{*}{$0.04(-0.04$ to 0.11$)$} \\
\hline Control & 74 & $0.68 \pm 0.25$ & $0.55 \pm 0.28$ & $0.13(0.07$ to 0.19$)$ & \\
\hline
\end{tabular}


if readings were consistently over target, understanding the need for intensification of treatment, visiting their physician for review and appropriate management by their physician. We included frail, elderly patients with a history of stroke, who are often excluded from trials, ${ }^{8,11,25}$ and patients with very high blood pressure or who were already taking 3 or more antihypertensive medications ${ }^{24,26-29}$ for whom therapeutic options may be limited. Although most patients in the intervention group were still monitoring their blood pressure after 12 months, this was more problematic for patients with disability, particularly those dependent on care providers not living with them. ${ }^{30}$

In addition, lack of consensus about appropriate home blood pressure targets in patients with a history of stroke may have contributed to clinical inertia. ${ }^{7}$ Participants saw their physician on average 5 times during the year, but, unlike in other studies, the physicians were not recruited to participate in the trial and did not receive an intensive educational intervention. ${ }^{4,11,22-25,31}$ Also, the physicians were not in research practices, ${ }^{11}$ and not all were supportive of home monitoring, as was found in a qualitative study of stroke patients' perceptions of home blood pressure monitoring. ${ }^{30}$ The qualitative study also suggested that monitoring encouraged some patients with blood pressure below target to take less medication, which is contrary to the advice they were given (Table 3 ). Finally, all patients with baseline blood pressure readings greater than $150 / 90 \mathrm{~mm} \mathrm{Hg}$ were advised to see their physician, potentially weakening the intervention effect.

Two other primary care-based trials of home monitoring included patients with hypertension who had a wide range of blood pressure readings. ${ }^{11,12}$ A US trial showed that monitoring with nurse support led to a significant reduction in systolic blood pressure despite a low baseline average of $125 \mathrm{~mm} \mathrm{Hg} .{ }^{11}$ By contrast, a UK trial involving selected patients with baseline blood pressure greater than $140 / 90 \mathrm{~mm} \mathrm{Hg}$ found that self-management in combination with telemonitoring was associated with a reduction in systolic blood pressure of $5.4 \mathrm{~mm} \mathrm{Hg} .{ }^{24}$ Although direct comparisons should be done cautiously, this compares to a reduction of $5.9 \mathrm{~mm} \mathrm{Hg}$ among corresponding patients in our post-hoc analysis (Table 2).

\section{Strengths and limitations}

Our trial was robust, with $93 \%$ follow-up and independent, blinded outcome assessment. The $81 \%$ recruitment rate among eligible patients in the outpatient clinics was high for a trial involv- ing patients with a history of stroke. Furthermore, the age, sex, ethnicity, and prevalence of atrial fibrillation, diabetes and past stroke in our study population were similar to those of 3356 consecutive patients recruited to our local stroke register during the period from Oct. 1, 2003, to Aug. 31, 2010, which suggests that our findings are generalizable to patients with a history of stroke. As in other trials, ${ }^{11,12}$ we included patients with hypertension who had a range of blood pressure readings. Many patients who use monitors have well-controlled blood pressure. Hence, it is important to include such patients in trials, as we have done, by including patients with hypertension who had a range of blood pressure readings. Nearly half of the participants had some disability, and almost a third of those in the home monitoring group required help from a care provider to measure their blood pressure. A quarter of the participants were from ethnic minorities, most were elderly and a fifth had diabetes. These patients are often excluded from trials but may wish to self-monitor; therefore, their inclusion in our trial added to the generalizability of the findings. The intervention was simple, relatively cheap and pragmatic: provision of a blood pressure monitor, with an average of 11 minutes teaching, a home visit and telephone support. It did not require Internet access, ${ }^{7,31}$ a landline or much technical expertise, ${ }^{24,25}$ and it did not increase the frequency of primary care consultations or patient anxiety. Data downloaded from the monitors showed that patients' records of their blood pressure readings were reliable..$^{32}$ Most trial participants interviewed for a qualitative substudy stated that they were highly motivated to reduce their risk of further strokes and felt empowered by monitoring. ${ }^{30}$

The main limitation of our study is that, although we achieved the required sample size, the power of the trial was adversely affected by the greater-than-expected variability in blood pressure $(\mathrm{SD} \pm 21 \mathrm{~mm} \mathrm{Hg}$ rather than \pm 16 $\mathrm{mm} \mathrm{Hg},{ }^{21,22}$ which is associated with an increased stroke risk $\left.{ }^{33}\right)$. The low power affected the ability to carry out subgroup analyses to determine which patients were more likely to benefit from monitoring. Also, there was a difference in blood pressure readings at baseline between the 2 groups, probably owing to random variability. This hindered interpretation of the unadjusted results. However, our primary analysis included baseline blood pressure as a covariate..$^{10}$

\section{Conclusion}

Overall, home monitoring did not improve blood pressure control among patients with hypertension and a history of stroke. It was associated 
with a fall in systolic pressure in patients who had uncontrolled blood pressure at baseline and those without disability due to stroke.

\section{References}

1. MacKay J, Mensah G. Atlas of heart disease and stroke. Oxford (UK): World Health Organization; 2004. p. 50.

2. PROGRESS collaborative group. Randomized trial of a perindopril-based blood-pressure-lowering regimen among 6105 individuals with previous stroke or transient ischaemic attack Lancet 2001;358:1033-41.

3. McAlister FA, Wilkins K, Joffres M, et al. Changes in the rates of awareness, treatment and control of hypertension in Canada over the past two decades. CMAJ 2011;183:1007-13.

4. Bray EP, Holder R, Mant J, et al. Does self-monitoring reduce blood pressure? Meta-analysis with meta-regression of randomized controlled trials. Ann Med 2010;42:371-86.

5. Cappuccio FP, Kerry SM, Forbes L, et al. Blood pressure control by home monitoring: meta-analysis of randomized trials. $B M J$ 2004;329:145-51.

6. Glynn LG, Murphy AW, Smith SM, et al. Interventions used to improve control of blood pressure in patients with hypertension. Cochrane Database Syst Rev 2010;(3):CD005182.

7. Agarwal R, Bills JE, Hecht TJW, et al. Role of home blood pressure monitoring in overcoming therapeutic inertia and improving hypertension control: a systematic review and meta-analysis. Hypertension 2011;57:29-38

8. McManus R, Glasziou P, Hayen A, et al. Blood pressure self monitoring: questions and answers from a national conference. BMJ 2008;337:a2738.

9. Parati G, Pickering TG. Home blood-pressure monitoring: US and European consensus. Lancet 2009;373:876-8.

10. Kerry S, Oakeshott P, Khong T, et al. Community based trial of home blood pressure monitoring with nurse-led telephone supports in patients with stroke or transient ischaemic attack recently discharged from hospital. Trials 2008;9:15. Available: www.trialsjournal.com/content/9/1/15 (accessed 2012 Oct. 12).

11. Bosworth HB, Olsen MK, Grubber JM, et al. Two self-management interventions to improve hypertension control: a randomized trial. Ann Intern Med 2009;151:687-95.

12. Halme L, Vesalainen R, Kaaja M, et al. Self-monitoring of blood pressure promotes achievement of blood pressure target in primary health care. Am J Hypertens 2005;18:1415-20.

13. Hodkinson HM. Evaluation of a mental test score for assessment of mental impairment in the elderly. Age Ageing 1972;1:233-8.

14. Bonita R, Beaglehole R. Recovery of motor function after stroke. Stroke 1988;19:1497-500.

15. Pickering TG, Houston Miller N, Ogedegbe G, et al. Call to action on use and reimbursement for home blood pressure monitoring. A joint scientific statement from theAmerican Heart Association, American Society of Hypertension, and Preventive Cardiovascular Nurses Association. Hypertension 2008;52:10-29.

16. The EuroQol Group. EuroQol — a new facility for the measurement of health-related quality of life. Health Policy 1990; 16:199-208.

17. Krasucki C, Ryan P, Ertan T, et al. The FEAR: a rapid screening instrument for generalized anxiety in elderly primary care attenders. Int J Geriatr Psychiatry 1999;14:60-8.

18. Parati G, Stergiou GS, Asmar R, et al. European Society of Hypertension guidelines for blood pressure monitoring at home: a summary report of the Second International Consensus Conference on home Blood Pressure Monitoring. J Hypertens 2008; 26:1505-26.

19. Chishti T, Harris T, Conroy R, et al. How reliable are stroke patients' reports of their numbers of general practice consultations over 12 months? Fam Pract 2012 Sept. 16. [Epub ahead of print]

20. Williams B, Lindholm LH, Sever P. Systolic pressure is all that matters. Lancet 2008;371:2219-21.

21. Dean SC, Kerry S, Cappuccio FP, et al. Pilot study of potential barriers to blood pressure control in patients with inadequately controlled hypertension. Fam Pract 2007;24:259-62.

22. McManus RJ, Mant J, Roalfe A, et al. Targets and self monitoring in hypertension: randomized controlled trial and cost effectiveness analysis. BMJ 2005;331:493.

23. Godwin M, Lam M, Birtwhistle R, et al. A primary care pragmatic cluster randomized trial of the use of home blood pressure monitoring on blood pressure levels in hypertensive patients with above target blood pressure. Fam Pract 2010;27:135-42.

24. McManus RJ, Mant J, Bray EP, et al. Telemonitoring and selfmanagement in the control of hypertension (TASMINH2): a randomized controlled trial. Lancet 2010;376:163-72.
25. Parati G, Omboni S, Albini F, et al. Home blood pressure telemonitoring improves hypertension control in general practice. The TeleBPCare study. J Hypertens 2009;27:198-203.

26. Zillich AJ, Sutherland JM, Kumbera PA, et al. Hypertension outcomes through blood pressure monitoring and evaluation by pharmacists (HOME study). J Gen Intern Med 2005;20:1091-6.

27. Márquez Contreras E, Martell Claros N, Gil Guillén V, et al. Efficacy of a home blood pressure monitoring programme on therapeutic compliance in hypertension: the EAPACUM-HTA study. J Hypertens 2006;24:169-75.

28. Mehos BM, Saseen JJ, MacLaughlin EJ. Effect of pharmacist intervention and initiation of home blood pressure monitoring in patients with uncontrolled hypertension. Pharmacotherapy 2000; 20:1384-9.

29. Vetter W, Hess L, Brignoli R. Influence of self-measurement of blood pressure on the responder rate in hypertensive patients treated with losartan: results of the SVATCH Study. Standard vs Automatic Treatment Control of COSAAR in Hypertension. J Hum Hypertens 2000;14:235-41.

30. Ovaisi S, Ibison J, Leontowitsch M, et al. A qualitative study of stroke patients' perceptions of home blood pressure monitoring. Br J Gen Pract 2011;61:e604-10.

31. Green BB, Cook AJ, Ralston JD, et al. Effectiveness of home blood pressure monitoring, web communication and pharmacist care on hypertension control: a randomized controlled trial. JAMA 2008;299:2857-67.

32. Shaw J, Kerry S, Sharma S, et al. Are stroke patients' reports of home blood pressure readings reliable? Cross sectional study. Family Practice 2011;28:110-22.

33. Rothwell PM, Howard SC, Dolan E, et al. Prognostic significance of visit-to-visit variability, maximum systolic blood pressure and episodic hypertension. Lancet 2010;375:895-905.

Affiliations: From the Centre for Primary Care and Public Health (Kerry), Barts and The London School of Medicine and Dentistry, Queen Mary, University of London, London, UK; the Stroke and Dementia Research Centre (Markus, Cloud), Basic Medical Sciences (Khong) and Population Health Sciences and Education (Tulloch, Coster, Ibison, Oakeshott), St. George's University of London, London, UK

Contributors: Sally Kerry and Pippa Oakeshott conceived the idea and designed the study. Hugh Markus and Teck Khong contributed to the study design. Sally Kerry was responsible for the statistical analysis and is the guarantor. Geoffrey Cloud, Jenny Tulloch, Denise Coster and Judith Ibison contributed substantially to acquisition of data. Sally Kerry and Pippa Oakeshott drafted the article, which Hugh Markus, Teck Khong, Geoffrey Cloud, Jenny Tulloch, Denise Coster and Judith Ibison revised. All of the authors approved the final version submitted for publication.

Funding: The main study was funded by The Stroke Association (grant no. TSA 2006/05). The feasibility study was funded by The Isaac Schapera Research Trust. Recruitment to the study was supported by the English National Institute of Health Research Clinical Stroke Research Network. Omron Healthcare UK Ltd. provided monitors for control patients after the end of the trial. (Monitors for intervention patients were provided from study funds.) St. George's University of London acted as sponsor for the study and reviewed the study design. The researchers had access to all study data and were independent of funder and sponsor in the analysis and interpretation of the data, writing the article and the decision to submit the manuscript for publication.

Acknowledgements: The authors thank the participants, their care providers and their family physicians; study administrator Cathy MacKay; collaborators Joyce Abili, Ajay Bhalla, Valerie Jones and Barry Moynihan; and researchers Deborah Obeng-Tuudah, Rachel Conroy, Reena Doshi, Gillian Kyei, Shanika Sharma, John Shaw, Stacey Bryan, Shazia Ovaisi, Emma Saunders, Ifan Jones, Celia Brown, Joanna O'Reilly and Sarah Kerry. The authors thank Rebecca Swinson for analysis of data from the St. George's Stroke Register. The members of the Data Monitoring Committee were Janet Peacock (chair), Lalit Kalra and Sonia Saxena. The committee reviewed recruitment and baseline data, and advised on the statistical analysis. 